Portland State University

PDXScholar

Electrical and Computer Engineering Faculty

Publications and Presentations

6-15-2017

\title{
Analysis and Testing of a Coaxial Magnetic Gearbox with Flux Concentration Halbach Rotors
}

\author{
Debarupa Som \\ University of North Carolina at Charlotte \\ Kang Li \\ University of North Carolina at Charlotte \\ Joshua Kadel \\ University of North Carolina at Charlotte \\ Jason Wright \\ University of North Carolina at Charlotte \\ Sina Modaresahmadi \\ University of North Carolina at Charlotte
}

See next page for additional authors

Follow this and additional works at: https://pdxscholar.library.pdx.edu/ece_fac

Part of the Electrical and Computer Engineering Commons

Let us know how access to this document benefits you.

\section{Citation Details}

Som, Debarupa; Li, Kang; Kadel, Joshua; Wright, Jason; Modaresahmadi, Sina; Bird, Jonathan; and William, W., "Analysis and Testing of a Coaxial Magnetic Gearbox with Flux Concentration Halbach Rotors" (2017). Electrical and Computer Engineering Faculty Publications and Presentations. 422.

https://pdxscholar.library.pdx.edu/ece_fac/422

This Post-Print is brought to you for free and open access. It has been accepted for inclusion in Electrical and Computer Engineering Faculty Publications and Presentations by an authorized administrator of PDXScholar. Please contact us if we can make this document more accessible: pdxscholar@pdx.edu. 
Authors

Debarupa Som, Kang Li, Joshua Kadel, Jason Wright, Sina Modaresahmadi, Jonathan Bird, and W. William 


\title{
Analysis and Testing of a Coaxial Magnetic Gearbox with Flux Concentration Halbach Rotors
}

\author{
Debarupa Som ${ }^{1}$, Kang Li (李康) ${ }^{1}$, Joshua Kadel $^{1}$, Jason Wright ${ }^{1}$, Sina Modaresahmadi ${ }^{1}$, Jonathan Z. Bird ${ }^{2}$, \\ W. William ${ }^{1}$
}

${ }^{1}$ University of North Carolina at Charlotte, Department of Electrical and Computer Engineering, Charlotte, NC, USA ${ }^{2}$ Portland State University, Department of Electrical and Computer Engineering, Portland, OR, USA

\begin{abstract}
Halbach array magnetic gearboxes have been discussed as being able to create high torque density. However, Halbach arrays are difficult to mechanically assembly and often the effective air-gap must be made larger in order to provide space for a retaining sleeve. This paper investigates the benefits of using an additional ferromagnetic retaining pole within the Halbach array structure. It is shown that utilizing this flux concentration ferromagnetic pole improves the torque density and can also help retain the magnets in place.
\end{abstract}

Index Terms - Analytical models, axial coupling, electromagnetic forces, Halbach rotor, radial coupling

\section{INTRODUCTION}

$\mathrm{M}$ AGNETIC gearboxes (MG) utilize magnetic field heterodyning to create speed change without physical contact [1-3]. As the air-gap torque is created using only magnet field excitation the torque density of a MG is not limited by the thermal limitations imposed by current excited machines. Recently a number of authors have proposed using a Halbach magnetic rotor $[4,5]$ to improve the torque density of a MG [6-8]. However, in order to retain the individual Halbach rotor magnets in place a mechanical rotor retaining sleeve is often needed. The retaining sleeve increases the effective air-gap and the increased air-gap then cancels out most, if not all, the torque density benefits of using a Halbach rotor when compared to using a more traditional rotor structure that does not need a retaining sleeve. As the Halbach rotor is considerably more difficult to assemble the use of a Halbach rotor appears to make the most sense in high-speed motor applications where a retaining sleeve and low harmonic content are essential requirements $[9,10]$.

A new type of flux concentration Halbach $(\mathrm{FCH})$ rotor typology was recently proposed by Hibbs et al. [11] in which an additional flux concentration ferromagnetic steel pole was added into the Halbach rotor. An example of FCH rotors used in a MG structure is shown in Fig. 1. By adding additional ferromagnetic pole pieces in front of the radially directed magnets the flux concentration Halbach type rotors can be constructed without the need for a mechanical retaining sleeve; this thereby enables a smaller air-gap to be maintained between rotors. This type of FCH structure was recently studied by Fu et al. [12] for use in a MG and Fu showed that it held particular promise. However, the steel poles in Fu's simulated design were selected to be $0.4 \mathrm{~mm}$ thick which appears to be impractically thin to construct. Apart from the additional patent by Toyota et al. [13] it would appear that few authors have studied this type of novel rotor typology.

Manuscript received March 10, 2017. Date of publication June, 2017; Corresponding authors: K. Li (email: kli10@uncc.edu), J. Z. Bird (e-mail: jonathan.bird@ieee.org).

Digital Object Identifier (inserted by IEEE).

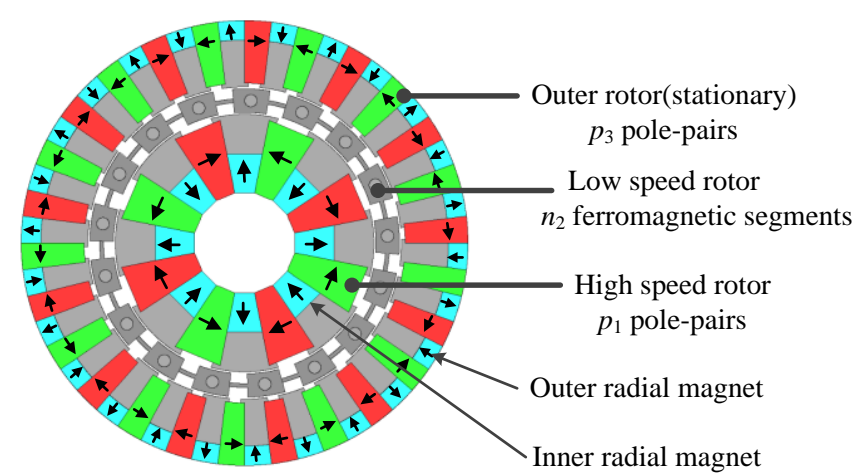

Fig. 1. Cross-sectional view of a 4.25:1 flux concentration Halbach rotor magnetic gearbox. The inner rotor as $p_{1}=4$ pole-pairs, the outer rotor has $p_{3}=13$ pole-pairs and there are $n_{2}=17$ ferromagnetic segments.

The object of this paper is to investigate the practical benefits of using this new FCH structure in a MG. Analysis and experimental results for a FCH-MG structure are presented.

\section{TORQUE TRANSFER}

In order for a coaxial MG to create speed change the field created by the inner rotor and outer rotor needs to be modulated. If the number of pole-pairs, $p_{1}$, on the inner rotor and number of pole-pairs, $p_{3}$, on the outer rotor are defined by

$$
n_{2}=p_{1}+p_{3}
$$

where $n_{2}$ is the number of ferromagnetic steel poles, then it can be shown that the magnetic fields can be coupled [1, 2]. The airgap fields can add and subtract resulting in a speed change between rotors that is defined by $[1,2]$

$$
n_{2} \omega_{2}=p_{1} \omega_{1}+p_{3} \omega_{3}
$$

where the subscripts denote rotor number. If the outer rotor is fixed $\left(\omega_{3}=0\right)$ the speed ratio is

$$
\omega_{1}=G_{12} \omega_{2}
$$

where $G_{12}=n_{2} / p_{1}$. For the example FCH-MG shown in Fig. 1 the gear ratio is $G_{12}=4.25$.

With $\omega_{3}=0$ the power relation between rotors is

$$
\left|T_{1}\right| \omega_{1}-\left|T_{2}\right| \omega_{2}=P_{l}
$$


where $T_{2}$ and $T_{1}$ are the peak torques on rotor 2 and rotor 1 respectively and $P_{l}$ are the total MG losses. The losses can be separated such that

$$
P_{l}=P_{h}+P_{e}+P_{m}
$$

where $P_{h}=$ hysteresis losses, $P_{e}=$ eddy current losses, $P_{m}=$ mechanical losses (primarily due to bearings and windage).

The active region volumetric torque density of a MG can be compared by using

$$
T_{v}=T_{2} /\left(\pi r_{o 3}^{2} d\right)
$$

$r_{o 3}=$ outer radius of the MG and $d=$ stack length.

\section{Flux CONCENTRATION Halbach Rotor DEsigN}

Table I summarizes the MG parameters used in the FCHMG design. The design is based on the flux-focusing MG design presented in [14] and shown in Fig. 2 and the performance of the FCH-MG will be compared with this base design.

A parameter sweep analysis when changing only the radial length of the inner and outer radial magnets was conducted as shown in Fig. 3 for the FCH-MG design. Based on this sweep analysis the outer and inner radial magnets were selected to be $10 \mathrm{~mm}$ and $6 \mathrm{~mm}$ in radial length respectively.

TABLE I.

FLUX CONCENTRATION HALBACH MAGNETIC GEARBOX PARAMETERS

\begin{tabular}{|c|l|c|c|}
\hline \multicolumn{2}{|l|}{ Description } & Value & Unit \\
\hline \multirow{4}{*}{$\begin{array}{l}\text { Inner } \\
\text { rotor }\end{array}$} & Inner radius, $r_{i 1}$ & 12.5 & $\mathrm{~mm}$ \\
\cline { 2 - 4 } & Outer radius, $r_{01}$ & 33.0 & $\mathrm{~mm}$ \\
\cline { 2 - 4 } & Pole pairs, $p_{1}$ & 4 & - \\
\cline { 2 - 4 } & Angular span, $\theta_{1}$ & $\pi /\left(2 p_{1}\right)$ & radians \\
\cline { 2 - 4 } & Radial length of radial magnet & 8.0 & $\mathrm{~mm}$ \\
\cline { 2 - 4 } & Radial length of azimuth magnet & 18.6 & $\mathrm{~mm}$ \\
\hline \multirow{4}{*}{$\begin{array}{l}\text { Cage } \\
\text { rotor }\end{array}$} & Inner radius, $r_{i 2}$ & 33.5 & $\mathrm{~mm}$ \\
\cline { 2 - 4 } & Outer radius, $r_{o 2}$ & 39.5 & $\mathrm{~mm}$ \\
\cline { 2 - 4 } & Pole pairs, $n_{2}$ & 17 & - \\
\cline { 2 - 4 } & Angular span, $\theta_{2}$ & 0.2443 & radians \\
\cline { 2 - 4 } & Connecting bridge, inner radius & 36 & $\mathrm{~mm}$ \\
\cline { 2 - 4 } & Connecting bridge, outer radius & 37 & $\mathrm{~mm}$ \\
\cline { 2 - 4 } & Rods, radius & 1.5875 & $\mathrm{~mm}$ \\
\hline \multirow{4}{*}{$\begin{array}{l}\text { Outer } \\
\text { rotor }\end{array}$} & Inner radius, $r_{i 3}$ & 40.0 & $\mathrm{~mm}$ \\
\cline { 2 - 4 } & Outer radius, $r_{03}$ & 57.0 & $\mathrm{~mm}$ \\
\cline { 2 - 4 } & Pole pairs, $p_{3}$ & 13 & - \\
\cline { 2 - 4 } & Angular span, $\theta_{3}$ & $\pi /\left(2 p_{3}\right)$ & $\mathrm{radians}$ \\
\cline { 2 - 4 } & Radial length of radial magnet & 4.0 & $\mathrm{~mm}$ \\
\cline { 2 - 4 } & Radial length of azimuth magnet & 14.0 & $\mathrm{~mm}$ \\
\hline \multicolumn{2}{|c|}{ Axial stack length, $d$} & 75 & $\mathrm{~mm}$ \\
\hline
\end{tabular}

Using finite element analysis (FEA) the peak torque for this FCH-MG was calculated to be $T_{2}=148.7 \mathrm{Nm}(201 \mathrm{Nm} / \mathrm{L})$ while the calculated peak torque for the flux focusing MG shown in Fig. 2 was $T_{2}=103.1 \mathrm{Nm}(139.5 \mathrm{Nm} / \mathrm{L})[14]$. This indicates that the FCH-MG typology should significantly increase the torque density of the MG, however this will be at the cost of increasing mechanical construction and assembly complexity.

In order to enable the FCH-MG to be assembled more easily back-iron was added, as shown in Fig. 4. The back-iron resulted in the radial magnets on the inner and outer rotor being reduced in length to $8 \mathrm{~mm}$ and $4 \mathrm{~mm}$ respectively. The back-iron also allowed the magnets to be made with rectangular and trapezoidal dimensions. These changes reduced the peak calculated torque to $T_{2}=142.2 \mathrm{Nm}(192.4 \mathrm{Nm} / \mathrm{L})$. The peak torque as a function of angular position is shown in Fig. 5, the torque ripple is low. The radial and azimuthal magnetic flux density within the FCH-MG is shown in Fig. 6. The saturation within the ferromagnetic poles can be seen in Fig. 6(a), the additional radial magnets greatly reduces the azimuthal flux leakage when compared to using flux barrier holes [14].

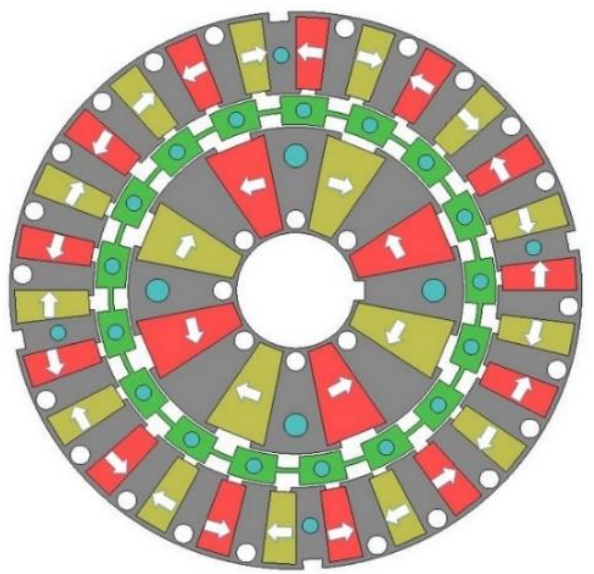

Fig. 2. Flux focusing magnetic gearbox with 4.25:1 gear ratio. The inner rotor as $p_{1}=4$ pole-pairs, the outer rotor has $p_{3}=13$ pole pairs. [14]

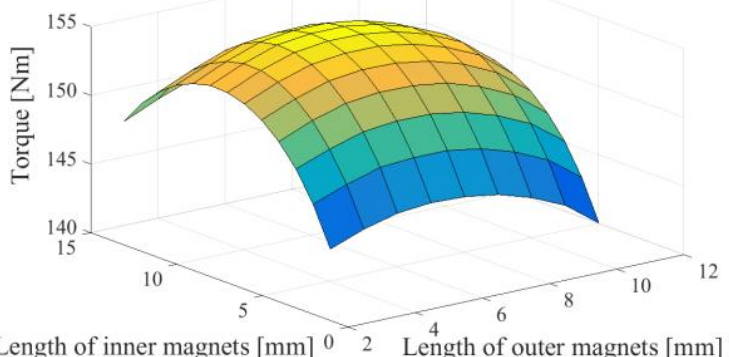

\footnotetext{
Length of inner magnets $[\mathrm{mm}]{ }^{0} \quad 2 \quad$ Length of outer magnets [mm]
}

Fig. 3. Inner and outer rotor radial magnet length parameter sweep analysis

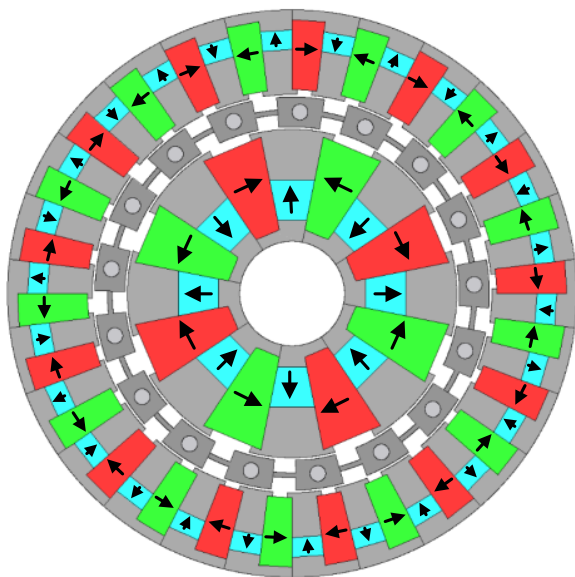

Fig. 4. Cross-sectional view of the 4.25:1 flux-concentration Halbach flux focusing magnetic gearbox designs with back-iron added in place. The inner rotor as $p_{1}=4$ pole-pairs, the outer rotor has $p_{3}=13$ pole pairs.

\section{EXPERIMENTAL PROTOTYPE}

The FCH-MG mechanical assembly is illustrated in Fig. 7 the central cage rotor is made of laminations while the inner and outer rotor poles are made using solid ferromagnetic steel. Solid steel was used for some parts as the primary purpose of the analysis was to investigate the construction feasibility and peak torque density (but not high speed efficiency) of this novel FCH-MG structure. The inner rotor steel poles are shown in 
Fig. 8(a) and the laminated cage rotor is shown in Fig. 8(b). The outer rotor assembly is shown in Fig. 8(c) and the fully assembled inner rotor and complete assembly is shown in Fig. 9. The inner rotor was not significantly more difficult than a typical rotor to construct. However, the outer rotor was significantly more difficult to assemble because there were a large number of assembly pieces.

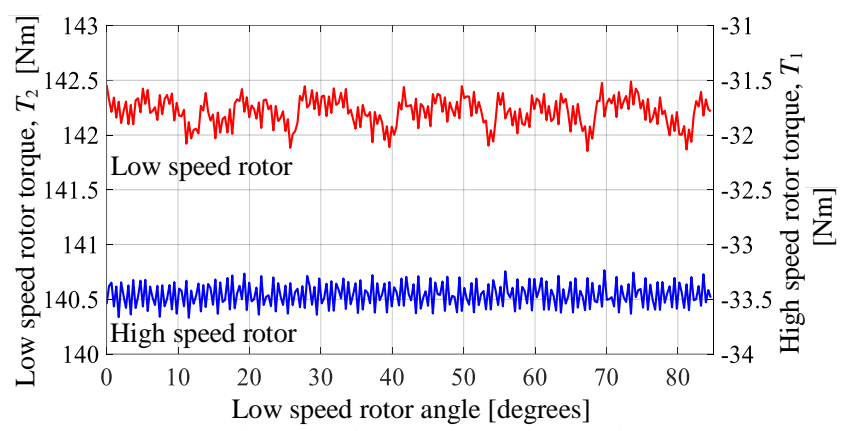

Fig. 5. Torque as a function of low-speed rotor angle for the high and low speed rotors when operating at calculated peak torque value.

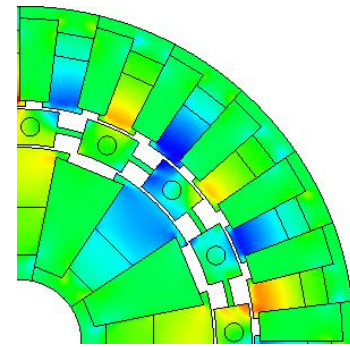

(a)

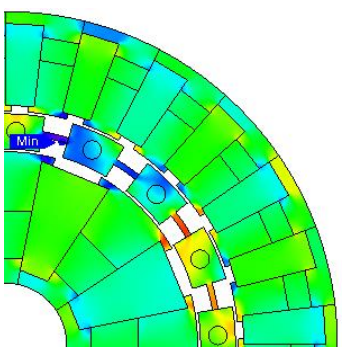

(b)

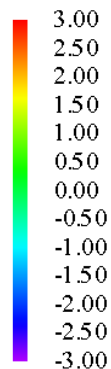

$-3.00$
Fig. 6. (a) Radial flux density $B_{r}$ and (b) azimuthal flux density $B_{\theta}$ for the flux concentration Halbach design with reduced $B_{r}$ values

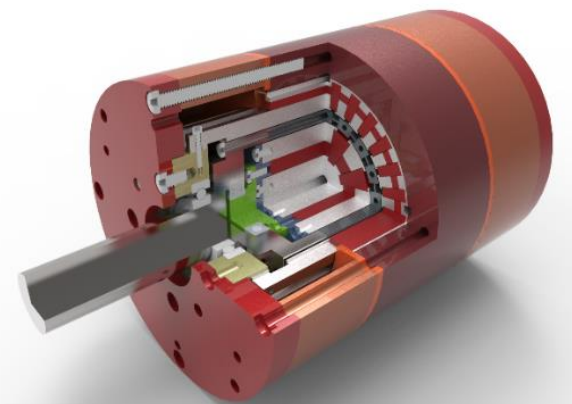

Fig. 7. Mechanical assembly of the flux concentration Halbach rotor magnetic gearbox

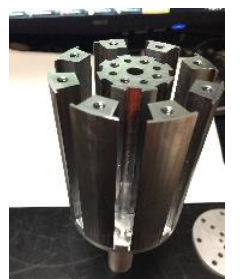

(a)

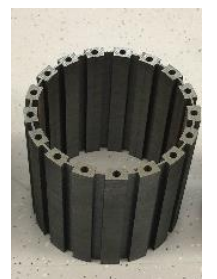

(b)

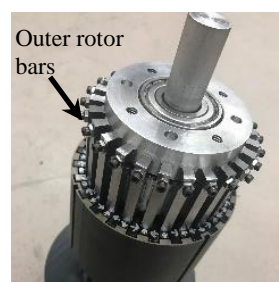

(c)
Fig. 8.(a) Inner rotor 1018 grade ferromagnetic poles and (b) low speed M19 ferromagnetic cage rotor and (c) outer rotor with 1018 ferromagnetic steel

The inner rotor field comparison, when surrounded by air, is shown in Fig. 10 and the harmonic comparison is shown in Fig. 11. Fig. 11 shows that the measured peak fundamental radial magnetic flux density value is $B_{r}=0.4 \mathrm{~T}$ while the fundamental of the FEA calculated value is $B_{r}=0.44 \mathrm{~T}$. In order to match the torque values the magnet's residual flux density value was reduced to $B_{m r}=1 \mathrm{~T}$. Using this reduced $B_{m r}$ value the MG torque was recalculated as shown in Fig. 12. The reduced residual flux density caused the calculated peak torque to reduce to $T_{2}=116.5 \mathrm{Nm}(152 \mathrm{Nm} / \mathrm{L})$.

The FCH-MG was experimentally tested by making load step changes using the test setup shown in Fig. 13, the measured torque step changes as a function of time are shown in Fig. 14. The peak torque was measured to be only $T_{2}=82.8 \mathrm{Nm}$. This measured torque value is $27 \%$ lower than the expected torque value and represents a measured torque density of only $112 \mathrm{Nm} / \mathrm{L}$.

An additional reason for the significantly lower torque than expected is believed to be due to the need to pre-stress the outer rotor bars, shown in Fig. 8(c), so as to prevent them from making contact with the low-speed rotor. This caused intentional deflection in the bars that resulted in a larger than expected airgap. A summary of the measured and calculated torque and torque density values is shown in Table II for the case when different discrepancies are accounted for.

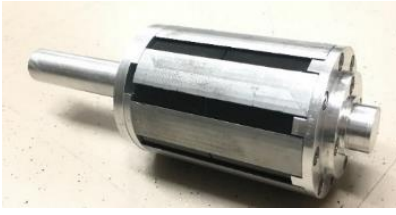

(a)

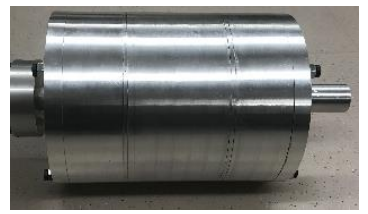

(b)
Fig. 9. (a) High-speed inner rotor assembly (b) fullly assembled MG

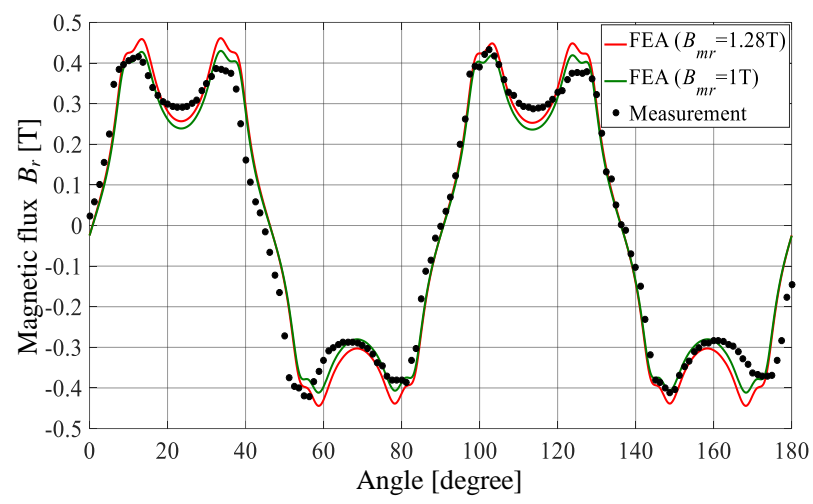

Fig. 10. Measured inner rotor field at $1.3 \mathrm{~mm}$ above the rotor surface. The inner rotor is surrounded by air. Also shown is the calculated magnetic flux density field values when $B_{m r}=1.28 \mathrm{~T}$ and $B_{m r}=1 \mathrm{~T}$.

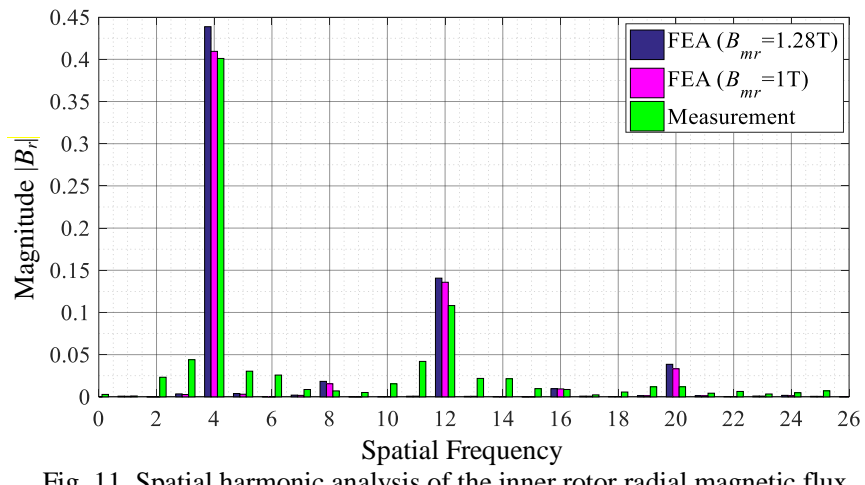

Fig. 11. Spatial harmonic analysis of the inner rotor radial magnetic flux density when surrounded by air. 
TABLE II.

SUMMARY OF CALCULATED AND MEASURED TORQUE AND TORQUE DENSITY

\begin{tabular}{|l|c|c|}
\hline Analysis type & $\begin{array}{c}\text { Peak } \\
\text { torque }[\mathrm{Nm}]\end{array}$ & $\begin{array}{c}\text { Peak torque density } \\
{[\mathrm{Nm} / \mathrm{L}]}\end{array}$ \\
\hline 2-D - original & 142 & 185 \\
\hline 2-D - reduced magnet $B_{r}$ & 118 & 154 \\
\hline 3-D - reduced magnet $B_{r}$ & 106 & 138 \\
\hline $\begin{array}{c}\text { 3-D - reduced } B_{r}, 1 \mathrm{~mm} \text { outer rotor } \\
\text { airgap }\end{array}$ & 92 & 120 \\
\hline Measured value & 82 & 107 \\
\hline
\end{tabular}

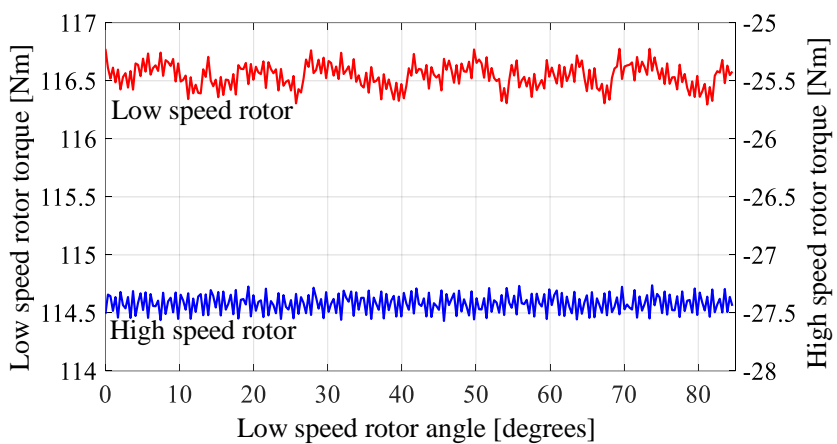

Fig. 12. Torque as a function of low-speed rotor angle for the high and low speed rotors when operating at calculated peak torque, using reduced magnet residual flux density $B_{m r}$.

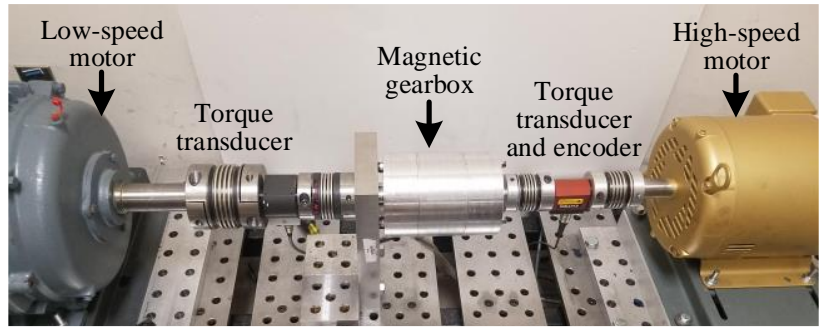

Fig. 13. Experimental test-stand for testing the FCH-MG

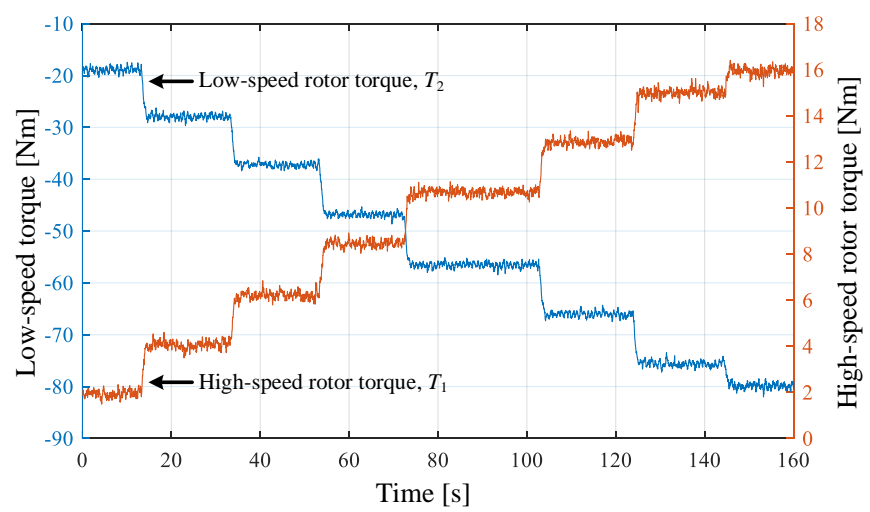

Fig. 14. Experimentally measured torque and at different load levels

\section{IDEAL SIZING ANALYSIS}

In section II it was shown that the inclusion of the ferromagnetic pole in front of the radial Halbach rotor magnet increased the torque density. This increase is caused by the steel pole concentrating the magnetic field thereby increasing the flux density around the air-gap. In order to properly understand the effect of using the ferromagnetic rotor pole an ideal MG typology as illustrated in Fig. 15 was studied. This design does not contain any magnet retaining lips nor additional back-iron and therefore enables the influence of the ferromagnetic rotor pole addition to be more clearly highlighted. Using the inner rotor magnet and steel pole lengths, as defined in Fig. 15, a scaling ratio can be defined as

$$
\Gamma_{i}=\frac{l_{i m}}{l_{i m}+l_{i s}}
$$

Similarly, an outer rotor magnet-steel scaling ratio can be defined as

$$
\Gamma_{o}=\frac{l_{o m}}{l_{o s}+l_{o m}}
$$

When $\Gamma_{i}=\Gamma_{o}=1$ the MG forms a 4 segment Halbach rotor MG when $\Gamma_{i}=\Gamma_{o}=0$ the MG rotors become spoke-type or flux focusing in typology. Using (7) and (8) the steel pole lengths were varied for the ideal MG design and the peak torque, torque density and mass torque density were computed. The results are shown in Fig. 16.

The active mass torque density was computed from

$$
T_{m}=\frac{T_{2}}{m_{s}+m_{m}}
$$

where $m_{s}$ is the ferromagnetic steel mass

$$
m_{s}=\frac{\pi d}{2} \rho_{s}\left[r_{o 1}^{2}-\left(r_{o 1}-l_{i s}\right)^{2}+2 r_{o 3}^{2}-r_{i 3}^{2}-\left(r_{o 3}-l_{o m}\right)^{2}\right]+\rho_{s} \theta_{2} n_{2}\left(r_{o 2}^{2}-r_{i 2}^{2}\right) d
$$

and $m_{m}$ is the magnet material mass

$$
m_{m}=\frac{\pi d}{2} \rho_{m}\left[r_{o 1}^{2}+\left(r_{i 1}+l_{i m}\right)^{2}-2 r_{i 1}^{2}+r_{o 3}^{2}-r_{i 3}^{2}+r_{o 3}^{2}-\left(r_{o 3}-l_{o m}\right)^{2}\right]
$$

where $\rho_{s}=7850 \mathrm{~kg} / \mathrm{m}^{3}$ and $\rho_{m}=7600 \mathrm{~kg} / \mathrm{m}^{3}$ are the mass density values for the steel and magnet material and $\theta_{2}$ is the fraction of angular span occupied by the cage rotor segments. The magnet mass torque density is then simply

$$
T_{m m}=\frac{T_{2}}{m_{m}}
$$

By studying Fig. 16 it was determined that the peak torque and torque density occurred at $\left(\Gamma_{i}, \Gamma_{o}\right)=(0.5,0.43)$. The torque density however does not change significantly when the outer radial magnet ratio is significantly greater than $\Gamma_{o}=0.2$. This is best seen by looking at Fig. 17 in which $\Gamma_{i}$ was held at $\Gamma_{i}=0.5$. Fig. 17(a) shows that there is minimal change in volumetric torque density between $\Gamma_{o}=0.2$ and $\Gamma_{o}=0.7$. The mass torque density, shown in Fig. 17 (b), exhibits a similar relationship. In contrast the magnet mass torque density is highest when $\Gamma_{o}=0$. This is not true for the inner rotor however Fig. 18(b) shows that the peak magnet mass torque density occurs at $\left(\Gamma_{i}, \Gamma_{o}\right)=$ $(0.2,0)$. Therefore, even the magnet mass torque density can benefit from having some percentage of ferromagnetic inserts.

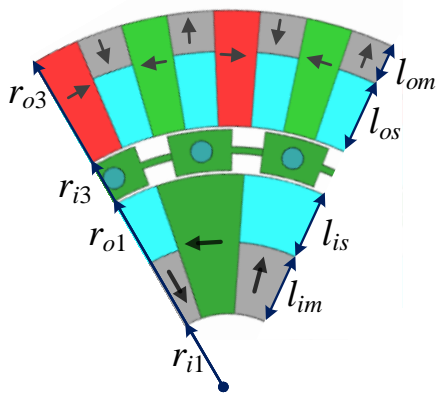

Fig. 15. Ideal model with dimensional definitions shown for the flux concentration Halbach magnetic gearbox. 


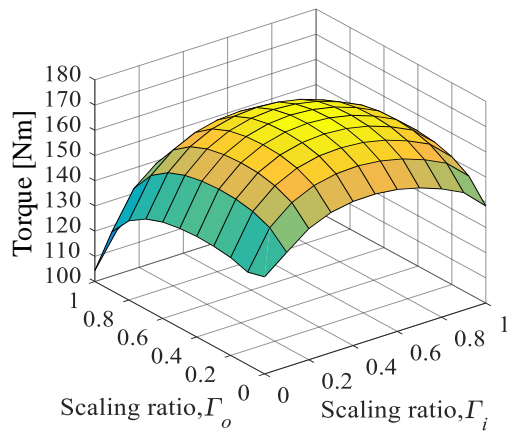

(a)

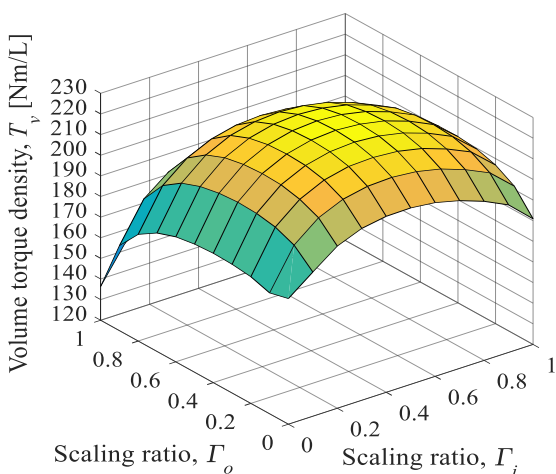

(b)

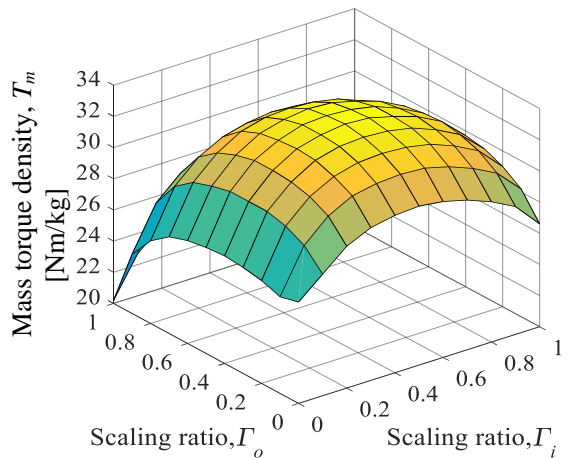

(c)

Fig. 16. The influence of inner rotor scaling ratio, $\Gamma_{i}$ and outer rotor scaling ratio, $\Gamma_{o}$, on (a) torque, (b) active region volumetric torque density and (c) active region mass torque density

In order to study the impact of the inclusion of the ferromagnetic segment the analysis presented here was for the case when the inner and outer rotor radial lengths were constant such that $\left(r_{o 1}-r_{i 1}\right)=20.5 \mathrm{~mm}$ and $\left(r_{o 3}-r_{i 3}\right)=17 \mathrm{~mm}$. However, the general conclusion that the inclusion of the ferromagnetic poles increases torque density still holds when a smaller rotor radial length is used. For example, Fig. 19 shows how the torque density changes when a different $r_{i 1}$ is used. It can be seen that in this case the peak volumetric torque density is not at either $\Gamma_{i}=1$ or $\Gamma_{i}=0$. A summary of the torque analysis results is provided in Table III.

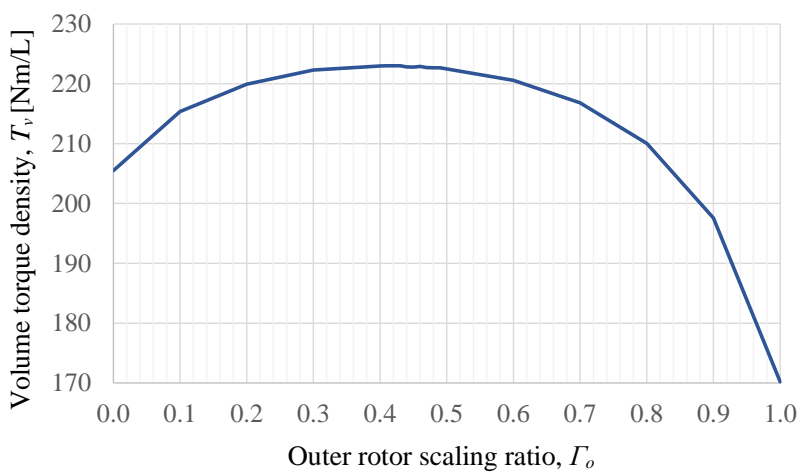

(a)

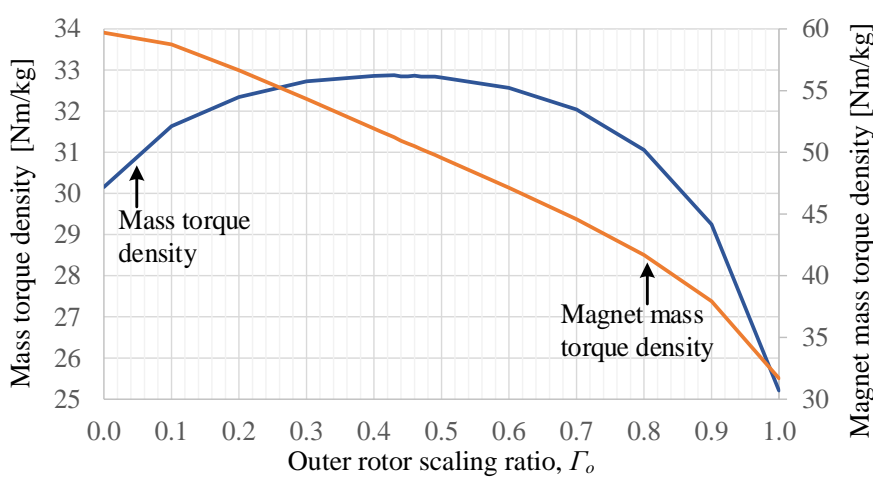

(b)

Fig. 17. Variation of (a) volume torque density, (b) mass torque density and torque-per-kg magnet mass as a function of outer scaling ratio for an inner scaling ratio of $\Gamma_{i}=0.5$.

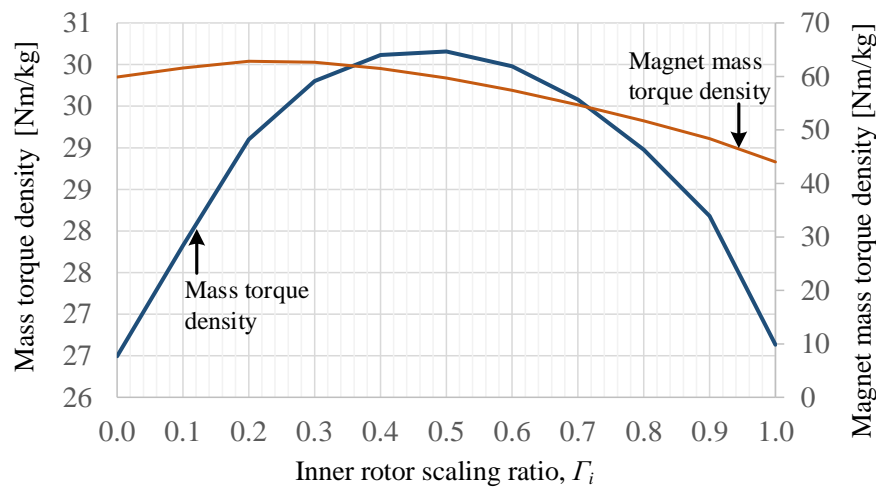

Fig. 18. Variation of mass torque density and magnet mass torque density as a function of inner scaling ratio when the outer scaling ratio is $\Gamma_{o}=0$.

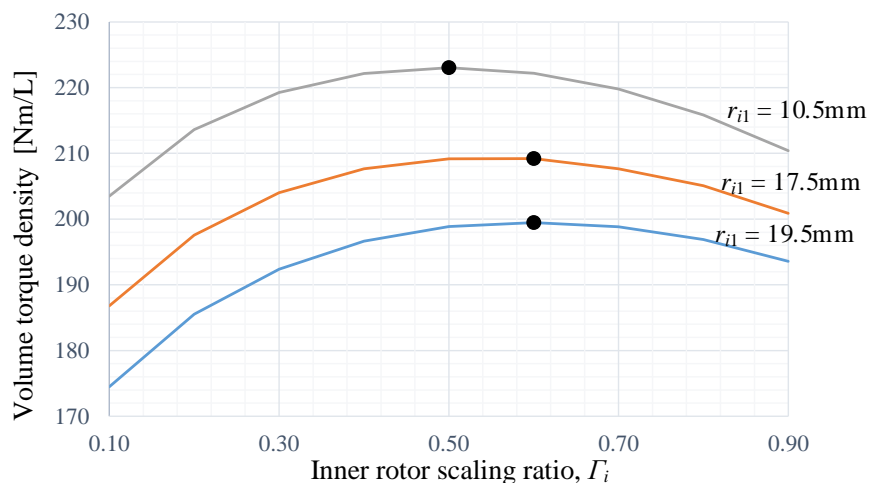

Fig. 19. The variation of torque density as a function of inner rotor scaling ratio for different inner radius values when the $\Gamma_{o}=0.43$. The peak torque density located is marked with a black marker. The outer rotor radii of the inner rotor was kept constant at $r_{o 1}=33 \mathrm{~mm}$. 
TABLE III

CALCULATED TORQUE DENSITY RESULTS WHEN VARYING THE INNER AND OUTER ROTOR SCALING RATIOS

\begin{tabular}{|c|c|c|c|c|}
\hline \multirow{2}{*}{ Rotor type } & \multirow{2}{*}{$\left(\Gamma_{i}, \Gamma_{o}\right)$} & \multicolumn{3}{|c|}{ Torque density } \\
\cline { 3 - 5 } & & $\begin{array}{c}\text { Volume, } \\
T_{v}[\mathrm{Nm} / \mathrm{L}]\end{array}$ & $\begin{array}{c}\text { Mass, } T_{m} \\
{[\mathrm{Nm} / \mathrm{kg}]}\end{array}$ & $\begin{array}{c}\text { Magnet mass, } \\
T_{m m}[\mathrm{Nm} / \mathrm{kg}]\end{array}$ \\
\hline Flux focusing rotor & $(0,0)$ & 171.2 & 25.4 & 56.7 \\
\hline Halbach rotor & $(1,1)$ & 153.8 & 22.9 & 25.5 \\
\hline \multirow{2}{*}{$\begin{array}{c}\text { Flux concentration } \\
\text { rotor }\end{array}$} & $(0.5,0.43)$ & 223.0 & 33 & 51.2 \\
\cline { 2 - 5 } & $(0.2,0)$ & 198.6 & 29.1 & 62.9 \\
\cline { 2 - 5 } & $(0.5,0)$ & 205 & 30 & 59.7 \\
\hline
\end{tabular}

\section{CONCLUSION}

A new type of FCH-MG has been presented and experimentally tested. The measured torque density was determined to be $112 \mathrm{Nm} / \mathrm{L}$. It was shown that by incorporating the ferromagnetic flux concentration poles within the Halbach type structure the torque density could be increased. However, this did increase the number of assembly parts and resulted in a more complicated assembly process. Therefore, using a FCH rotor structure is perhaps best considered in situations where the rotor has a low number of pole-pairs.

\section{ACKNOWLEDGMENTS}

The authors would gratefully like to thank the JMAG corporations for the use of their FEA software. This material is based upon work supported by the Department of Energy under grant No. DE-EE0006801 as well as a North Carolina Ocean Energy grant.

\section{REFERENCES}

[1] T. B. Martin, "Magnetic Transmission," USA Patent 3,378,710, 1968.

[2] K. Atallah, S. D. Calverley, and D. Howe, "Design, analysis and realisation of a high-performance magnetic gear," IEE Proc.-Electr. Power Appl., vol. 151, no. 2, pp. 135-143, 2004.

[3] P. O. Rasmussen, T. O. Andersen, F. T. Jorgensen, and O. Nielsen, "Development of a high-performance magnetic gear," IEEE Trans. Ind. Appl., vol. 41, no. 3, pp. 764-770, 2005.

[4] K. Halbach, "Design of permanent multipole magnets with oriented rare earth cobalt material," Nucl Instr. and Meth., vol. 187, no. pp. 1$10,1980$.

[5] H. A. Shute, J. C. Mallinson, D. T. Wilton, and D. J. Mapps, "Onesided fluxes in planar, cylindrical, and spherical magnetized structures," IEEE. Trans. Magn., vol. 36, no. 2, pp. 440-451, 2000.

[6] L. Jian, K. T. Chau, Y. Gong, J. Z. Jiang, C. Yu, and W. Li, "Comparison of coaxial magnetic gears with different topologies," IEEE Trans. Magn., vol. 45, no. 10, pp. 4526-4529, 2009.

[7] L. Jian and K. T. Chau, "A Coaxial Magnetic Gear With Halbach Permanent-Magnet Arrays," IEEE Trans. Energy Conv., vol. 25, no. 2, pp. 319-328, 2010.

[8] A. Penzkofer and K. Atallah, "Magnetic Gears for High Torque Applications," IEEE Trans. Magn., vol. 50, no. 11, p. Article\#: 81047042014.

[9] C. A. Gallo, "Halbach Magnetic Rotor Development," Report \# NASA/TM-2008-215056, Glenn Research Center, Cleveland, OH, USAFeb. 2008.

[10] Z. Q. Zhu and D. Howe, "Halbach permanent magnet machines and applications: a review," IEE Proc. - Electric Power App., vol. 148, no. 4, pp. 299-308, 2001.

[11] B. D. Hibbs and D. X. Phan, "Flux Concentrator for ironless motors," USA Patent US 2010/0181858 A1, Jul. 222010.

[12] W. N. Fu and L. Li, "Optimal Design of Magnetic Gears With a General Pattern of Permanent Magnet Arrangement," IEEE Trans. Applied Super., vol. 26, no. 7, pp. 1-5, 2016.

[13] A. Toyota, T. Shikayama, and M. Kakihara, "Periodic magnetic field generation device, and linear motor and rotary motor using the same," USA Patent US 2011/0012440 A1, Jan 202011.
[14] K. Uppalapati, K. J., J. Wright, L. K., J. Z. Bird, and W. Williams, "A low assembly cost coaxial magnetic gearbox," presented at the South. Power Elec. Conf., Auckland, NZ, Dec 5-8, 2016. 